\title{
Mixed H2/H Pitch Control of Wind Turbine with a Markovian Jump Model
}

\author{
Lin, Zhongwei; Liu, Jizhen; Wu, Qiuwei; Niu, Yuguang
}

Published in:

International Journal of Control

Link to article, DOI:

$10.1080 / 00207179.2016 .1272716$

Publication date:

2018

Document Version

Peer reviewed version

Link back to DTU Orbit

Citation $(A P A)$ :

Lin, Z., Liu, J., Wu, Q., \& Niu, Y. (2018). Mixed H2/H Pitch Control of Wind Turbine with a Markovian Jump Model. International Journal of Control, 91(1), 156-169. https://doi.org/10.1080/00207179.2016.1272716

\section{General rights}

Copyright and moral rights for the publications made accessible in the public portal are retained by the authors and/or other copyright owners and it is a condition of accessing publications that users recognise and abide by the legal requirements associated with these rights.

- Users may download and print one copy of any publication from the public portal for the purpose of private study or research.

- You may not further distribute the material or use it for any profit-making activity or commercial gain

- You may freely distribute the URL identifying the publication in the public portal 


\section{Mixed $\mathrm{H}_{2} / \mathrm{H}_{\infty}$ Pitch Control of Wind Turbine with a Markovian Jump Model}

\section{Zhongwei Lin, Jizhen Liu, Qiuwei Wu \& Yuguang Niu}

To cite this article: Zhongwei Lin, Jizhen Liu, Qiuwei Wu \& Yuguang Niu (2016): Mixed $\mathrm{H}_{2} / \mathrm{H}_{\infty}$ Pitch Control of Wind Turbine with a Markovian Jump Model, International Journal of Control, DOI: $10.1080 / 00207179.2016 .1272716$

To link to this article: http://dx.doi.org/10.1080/00207179.2016.1272716

Accepted author version posted online: 15

Dec 2016.

Submit your article to this journal ¿

山ll Article views: 8

View related articles $\sqsubset$

View Crossmark data \lceil 


\title{
Publisher: Taylor \& Francis
}

\author{
Journal: International Journal of Control
}

DOI: http://dx.doi.org/10.1080/00207179.2016.1272716

\section{Mixed $H_{2} / H_{\infty}$ Pitch Control of Wind Turbine with a}

\author{
Markovian Jump Model \\ Zhongwei Lin ${ }^{1 *}$ Jizhen $\mathrm{Liu}^{1}$, Qiuwei $\mathrm{Wu}^{2}$ and Yuguang Niu ${ }^{1}$ \\ ${ }^{1}$ State Key Laboratory of Alternate Electrical Power System with Renewable Energy Sources, \\ North China Electric Power University, Beijing 102206, P R. China \\ ${ }^{2}$ Center for Electric Power and Energy, Department of Electrical Engineering, \\ Technical University of Denmark, Kgs. Lyngby 2800, Denmark
}

\begin{abstract}
This paper proposes a Markovian jump model and the corresponding $H_{2} / H_{\infty}$ control strategy for the wind turbine driven by the stochastic switching wind speed, which can be used to regulate the generator speed in order to harvest the rated power while reducing the fatigue loads on the mechanical side of wind turbine. Through sampling the low-frequency wind speed data into separate intervals, the stochastic characteristic of the steady wind speed can be represented as a Markov process, while the high-frequency wind speed in the each interval is regarded as the disturbance input. Then, the traditional operating points of wind turbine can be divided into separate subregions correspondingly, where the model parameters and the control mode can be fixed in each mode. Then, the mixed $H_{2} / H_{\infty}$ control problem is discussed for such a class of Markovian jump wind turbine working above the rated wind speed to guarantee both the disturbance rejection and the mechanical loads objectives, which can reduce the power volatility and the generator torque fluctuation of the whole transmission mechanism effieiently. Simulation results for a $2 \mathrm{MW}$ wind turbine show the effectiveness of the proposed method.

Keywords: Wind turbine, Markovian jump systems, mixed $H_{2} / H_{\infty}$ control, pitch control.

${ }^{0}$ This work is partially supported by the National Basic Research Program of China (973 Program) (Grant No. 2012CB215203), the National Natural Science Foundation of China (No. 61203043, No. 51036002) and the Fundamental Research Funds for the Central Universities.

*Corresponding author. E-mail address: lzw@ncepu.edu.cn, linzhongwei2003@tom.com
\end{abstract}




\section{Introduction}

In recent years, the increasing size of wind turbine has been inducing heavier subsystems and higher mechanical stresses on the turbine, while more installed capacity of wind turbines causes a larger fraction of wind power in the power grid. Accordingly, the wind turbine technology has been advancing rapidly while new challenges are appearing for the future growth of the technology. Many experts and scholars have put into the study of seeking some better control strategies to overcome these potential challenges. Currently, the acknowledged strategy of wind turbine is focusing on both power and fatigue loads, that is, to seek the maximum wind energy conversion efficient when below the rated wind speed, or to stabilize the output power to the rated power when above the rated wind speed, which is in the premise of less fatigue loads. Especially, when the wind turbine works above the rated wind speed, the pitch control is used to reduce the overload phenomenon on the mechanical and electrical parts of the unit, see $[1,2,3,4]$. Also, the volatility of the wind speed can lead to the large range variety of operating points, while the turbulent wind speed can lead to the extra fatigue loads and output power ripple, which will cause a significant negative impact on the wind turbine mechanical side and the stability of the power grid [5]. Therefore, the control objective is to change the wind energy utilization coefficient of wind turbine through using the pitch controller, to stabilize the output power near the power rating adapting to the large range variety of operating points, restrain the wind disturbance and reduce the fatigue loads [6].

Traditional techniques concentrate on the control design based on several operating points due to the strong nonlinearity of wind turbine, and the proportional-integral (PI) control is usually adopted for one or more operating points. However, when the operating point deviates from the operating point, the corresponding control effect will decline. Moreover, the stochastic characteristic of wind speed causes the the frequent switchings of wind turbine operating points, which brings further difficulty for control design to satisfy the above mentioned control strategy. Many authors have widely applied the modern control theory in the design of wind turbine control, such as linear-parameter-varying (LPV) control, model predictive control (MPQ) or nonlinear feedback control, see [7, 8, 9, 10, 11, 12, 13, 18, 19, 33, 21, 22, 23, 28, 29, 30, 33]. Especially, [7] and [8] have designed the control law for wind turbine based on the gain scheduling method, where the switching law is satisfying a specific condition. However, it is very complicated to solve the LPV controller [11], and the switching is far away from the realistic stochastic property.

On the other hand, there have been many research related to the stochastic property of wind speed in a specified wind farm, see [14, 15, 16, 17], etc. Especially, [14] and [15] have analyzed the time series data of wind speed by applying the Markov process. Most work only concentrate on the static information of wind speed for choosing farm, or generate wind speed for testing. Meanwhile, Markovian jump system 
has been well investigated due to the probabilistic description of model parameters switchings induced by external causes, e.g., random faults, unexpected events, uncontrolled configuration changes, see [26, 27] and the references therein. However, up to date, there has been no related research work combining the stochastic property of wind speed into the control strategy of wind turbine, which is an interesting topic and leads to this study. Another challenge is that, once the wind turbine has been modelled into Markovian jump systems, how to design the corresponding control to satisfy the desired performances of wind turbine, where the traditional techniques are not appropriate due to the stochastic switchings of wind turbine operating points.

This paper is aimed at regulating the generator speed of wind turbine through the state feedback $H_{2} / H_{\infty}$ control, which is driven by the frequently switching wind speed, and the switching between operating points satisfies the stochastic property of steady wind speed. More concretely, the main contribution of this paper contains the following aspects:

- The wind turbine driven by the switching wind speed is modeled into Markovian jump systems, which has represented the stochastic characteristic of the wind speed variation into a Markov process. Through sampling the low-frequency wind speed data of the specified wind turbine into separate intervals, the stochastic characteristic of wind speed variation can be represented as a Markov process, then the traditional operating points of wind turbine can be divided into separate subregions correspondingly, where the model parameters and the control mode can be fixed in each mode.

- For the Markovian jump systems representing the wind turbine switching stochastically between different operating points, the mixed $H_{2} / H_{\infty}$ control problem is discussed to guarantee both the disturbance rejection and the mechanical loads objectives, where the controller design constraints include $H_{\infty}$ problem form better generator speed regulation, and $H_{2}$ problem for less fatigue loads.

The rest of this paper is organized as follows: Section 2 describes the Markov process model of the steady wind speed, while the high-frequency wind speed in the each interval is regarded as the disturbance input. In Section 3, due to the fact that the operating points is corresponding to the steady wind speed, the wind turbine is modeled into Markovian jump system. Then, the mixed $H_{2} / H_{\infty}$ control problem is discussed for the linearized Markovian jump model of wind turbine in terms of LMIs in Section 4. In Section 5 , the proposed method is applied on a $2 \mathrm{MW}$ wind turbine with the historical wind speed data. Section 6 concludes this paper.

For convenience, we adopt the following notations: $A^{\prime}$ : the transpose of a matrix or vector $A$. $A \geq$ $\theta(A>0)$ : the positive semi-definite (positive-definite) matrix. $I$ : the identity matrix. $R^{n}: n$-dimensional real Euclidean space. 


\section{The Markov model for average wind speed}

In this section, the stochastic property of wind speed is modelled into the Markov process for the further control design. For the wind turbine control design, several operating points are usually established corresponding to the separate wind speed due to the nonlinear terms of the wind turbine model. However, when the wind speed switches between different operating points frequently, the designed control effect will be reduced significantly. Herein, we try to extract the stochastic property of wind speed and then apply to the wind turbine control design.

Firstly, in order to extract the stochastic property of wind speed, the actual wind speed $V$ is divided into the average wind speed $V_{s}$ and disturbance wind speed $V_{w}$, which is corresponding to the lowfrequency steady part and high-frequency turbulence part, respectively:

$$
V(t)=V_{s}(t)+V_{w}(t)
$$

As mentioned in [11], at any time interval $t_{p}$ around $t_{0}$, the steady part $V_{s}$ can be defined as

$$
V_{s}(t)=\frac{1}{t_{p}} \int_{t_{0}-t_{p} / 2}^{t_{0}+t_{p} / 2} V(t) d t,
$$

where $t_{p}$ ranges from 10 to 20 minutes, and $V_{w}$ corresponds to the high-frequency part whose durations are less than 10 minutes.

Motivated by the research of [14] and [15], the stochastic property of the average wind speed $V_{s}(t)$ can be presented as a Markov process, which is based on the transitional probability matrices of various time steps and sample datas. Most often, a first-order continuous-time Markov chain implies preservation of statistical parameters and especially the first-order autocorrelation coefficient in the synthetic sequences. In order to calculate the Markov chain transitional probabilities, initially the wind speed variation domain is divided into many states, which is determined according to the average $V_{s}$ and standard deviation $S_{v}$ of the available wind speed time series. The stages are arranged with the average and various standard deviations of subdivisions. The number of states is determined according to the variation domain of the wind speed values as in Table 1 , which has divided the wind speed into $N$-regions between the rated wind speed and the cut-out-wind speed.

In general, let the number of states at each time instant be $N(N$ in Table 1 as to the above rated wind speed). Hence, there will be $N \times N$ transitions between two successive time instances. According to $6.4,2$ in $\{18]$, the transition probabilities $p_{i j}$ from a state at time $k$ to another state at time $k+1$, i.e. can be represented as

$$
\begin{gathered}
p_{i j}=P\left(r_{k+1}=j \mid r_{k}=i\right), \\
p_{i j}=\frac{\text { observed transitions from state } i \text { to } j}{\text { ocurrences of state } i} .
\end{gathered}
$$


Accordingly, the transition probability matrix $P_{k, k+1}$ can be prepared from the observed wind speed data:

$$
P_{k, k+1}=\left[\begin{array}{ccccc}
p_{11} & p_{12} & p_{13} & \ldots & p_{1 N} \\
p_{21} & p_{22} & p_{23} & \ldots & p_{2 N} \\
p_{31} & p_{32} & p_{33} & \ldots & p_{3 N} \\
\vdots & \vdots & \vdots & \vdots & \vdots \\
p_{N 1} & p_{N 2} & p_{N 3} & \ldots & p_{N N}
\end{array}\right]
$$

with $p_{i j} \geq 0$ for $i, j \in\{1,2, \cdots, N\}$, and

$$
\sum_{j=1}^{n} p_{i j}=1
$$

The above matrix shows all the transition probabilities $p_{i j}$ of the average wind speed in state $i$ to state $j$. Hence, through classifying the average wind speed into several regions, and sampling the wind speed data in the separate wind speed region, we can calculate the transitions probabilities (4) between different wind speed regions where the low-frequency average wind speed locates in. In this way, the stochastic properties of the wind speed can be represented into the Markor process $r(k)$ :

$$
V(k)=V_{s}(k, r(k))+V_{w}(k)
$$

\section{Wind turbine with a Markovian jump model}

In this section, the stochastic property of wind speed is combined with the wind turbine, which sustains the stochastic controlled wind turbine model, due to the fact that the switchings of wind turbine operating points are closely connected to the switchings of steady wind speed between different regions. The detailed modelling process is give as follows:

\subsection{Wind turbine, Transmission Mechanism and Generator Subsystems}

The wind turbine control system consists of the three subsystems: the wind turbine, the transmission mechanism and the generator, see Fig. 1. Following with the operating points determined by the wind speed, the wind turbine can be modelled as the two-mass model given as follows:

(i) The wind turbine is the drive of the whole system. The rotor torque can be expressed as:

$$
\begin{gathered}
T_{r}=\frac{1}{2} C_{p}(\lambda, \beta) \rho \pi R^{2} \frac{V^{3}}{\omega_{r}}, \\
\lambda=\frac{\omega_{r} R}{V},
\end{gathered}
$$

where $T_{r}$ is the rotor torque of wind turbine, $R$ is the rotor radius, $\rho$ is the air density, $V$ is the wind speed, $\omega_{r}$ is the rotor speed, $\lambda$ is the tip speed ratio, $\beta$ is the pitch angle. The wind-power utilization coefficient $C_{p}(\lambda, \beta)$ is approximately calculated and modelled under different wind speed conditions for 
a specific wind turbine [13], which is a nonlinear function respect to $\lambda$ and $\beta$, and can be expressed with the parameter $c_{1}-c_{8}$ as follows:

$$
C_{p}(\lambda, \beta)=c_{1}\left(\frac{c_{2}}{\lambda^{*}}-c_{3} \beta-c_{4}\right) e^{-\frac{c_{5}}{\lambda^{*}}}+c_{6} \lambda
$$

with

$$
\lambda^{*}=\left(\frac{1}{\lambda+c_{7} \beta}-\frac{c_{8}}{\beta^{3}+1}\right)^{-1} .
$$

The dynamic characteristics of wind turbine can be expressed as:

$$
J_{r} \dot{\omega}_{r}=T_{r}-B_{s t i f} \theta-K_{d a m p} \dot{\theta}
$$

where $J_{r}$ is the equivalent moment of inertia for wind turbine rotor; $B_{\text {stif }}$ is the equivalently torsional stiffness of shaft; $K_{\text {damp }}$ is the equivalently damping factor of shaft; $\theta$ is the equivalently torsional angle of shaft, and satisfying

$$
\dot{\theta}=\omega_{r}-\frac{1}{N_{g}} \omega_{g} .
$$

The actuator of pitch angle control can be express as:

$$
\dot{\beta}=\frac{1}{\tau}\left(\beta_{r}-\beta\right)
$$

where $\beta_{r}$ is the referenced pitch angle, $\tau$ is the time constant of actuator.

Assume that the drag torque $T_{d}$ concentrates on the wind rotor, which can be expressed as:

$$
T_{d}=K_{d} \omega_{r}
$$

where $K_{d}$ is the damping coefficient of the transmission mechanism.

(ii) The dynamic characteristic of the generator can be expressed as:

$$
J_{g} \dot{\omega}_{g}=\frac{B_{s t i f}}{N_{g}} \theta+\frac{K_{d a m p}}{N_{g}} \dot{\theta}-T_{g},
$$

where $J_{g}$ is the equivalent moment of inertial for generator rotor; $T_{g}$ is the generator torque; $\omega_{g}$ is the generator rotor speed. Due to the smaller time constant, it has rapid response to the order from the mechanical side. In its workspace, its characteristic can be approximated by piecewise linear functions. If $\omega_{z}$ is defined as the control output, the linear torque characteristic in the normal workspace can be represented as

$$
T_{g}=B_{g}\left(\omega_{g}-\omega_{z}\right)
$$

where $B_{g}$ is the torque-speed curve slope of induction generators. The generator output power can be expressed as

$$
P=\omega_{g} T_{g}
$$




\subsection{Comprehensive Markovian jump model for wind turbine}

Select the state variable $x_{h}=\left[\theta, \omega_{r}, \omega_{g}, \beta\right]^{\prime}$ and the control variable $u=\left[\beta_{r}, \omega_{z}\right]$. From (6)-(14), the nonlinear comprehensive model of wind turbine can be formulated as:

$$
\dot{x}_{h}=f\left(x_{h}, t\right)+g\left(x_{h}\right) u,
$$

where

$$
f\left(x_{h}, t\right)=\left[\begin{array}{c}
\omega_{r}-\frac{1}{N_{g}} \omega_{g} \\
\frac{1}{J_{r}} T_{r}-\frac{K_{d a m p}}{J_{r}} \omega_{r}+\frac{K_{d a m p}}{J_{r} N_{g}} \omega_{g}-\frac{B_{s t i f}}{J_{r}} \theta \\
\frac{K_{d a m p}}{J_{g} N_{g}} \omega_{r}-\left(\frac{K_{d a m p}}{J_{g} N_{g}^{2}}+\frac{B_{g}}{J_{g}}\right) \omega_{g}+\frac{B_{s t i f}}{J_{g} N_{g}} \theta \\
-\frac{1}{\tau} \beta
\end{array}\right], g\left(x_{h}\right)=\left[\begin{array}{cc}
0 & 0 \\
0 & 0 \\
0 & \frac{B_{g}}{J_{g}} \\
\frac{1}{\tau} & 0
\end{array}\right] .
$$

Considering (5) and (15), applying the Taylor expansion on the steady wind speed $V_{s}$, omitting the higher order terms, can be expressed as:

$$
T_{r}=T_{r 1}\left(V_{s}\right)+T_{r 2}\left(V_{s}\right) V_{w},
$$

where

$$
\begin{aligned}
& T_{r 1}\left(V_{s}\right)=\left.T_{r}\right|_{V=V_{s}}=\frac{1}{2} C_{P}(\lambda, \beta) \rho \pi R^{2} \frac{V_{s}^{3}}{w_{r}} \\
& T_{r 2}\left(V_{s}\right)=\left.\frac{\partial T_{r}}{\partial V}\right|_{V=V_{s}}=\left.\left(3 V^{2} C_{p}(\lambda, \beta)-\frac{\partial C_{p}(\lambda, \beta)}{\partial \lambda} \omega_{r} V R\right)\right|_{V=V_{s}} .
\end{aligned}
$$

Because the steady wind speed $V_{s}$ can vary the steady operating points of wind turbine, it can be defined as the varying parameter $r_{t}$ to schedule the whole wind power generation process. Consequently, it yields the following nonlinear Markovian jump system model with the perturbed term for wind turbine:

$$
\dot{x_{h}}=\widehat{f}\left(x_{h}, t\right)+g_{u}\left(x_{h}\right) u+g_{w}\left(x_{h}, t\right) V_{w}
$$

where

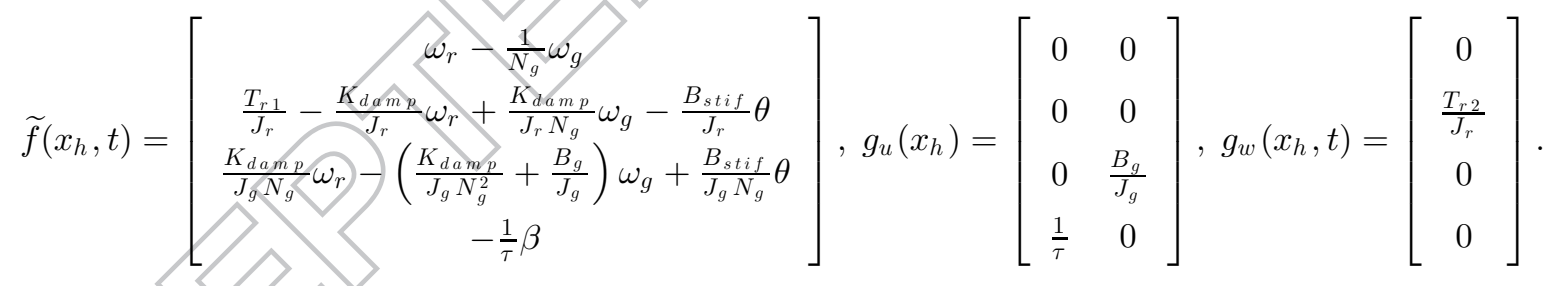

For (16), we define the operating points as $\bar{x}_{i}=\left[\bar{\theta}_{i}, \bar{\omega}_{r i}, \bar{\omega}_{g i}, \bar{\beta}_{i}\right]^{\prime}$ with the parameter $i$ which is corresponding to the current operating point, then choose the state variable

$$
x=\left(\triangle \theta, \triangle \omega_{r}, \triangle \omega_{g}, \triangle \beta\right)^{\prime}=\left(\theta-\bar{\theta}_{i}, \omega_{r}-\bar{\omega}_{r i}, \omega_{g}-\bar{\omega}_{g i}, \beta-\bar{\beta}_{i},\right)^{\prime} .
$$

Note that, the operating points are chosen within the corresponding steady wind speed subregion $V_{s}(i)$. As shown in Table 2, the whole operating region of the wind turbine control system (16) consist of $N$-operating subregions. 
Then, applying the Taylor expansion around the corresponding operating points $\bar{x}_{i}$, system (16) can be linearized into a set of linear subsystems with the following form:

$$
\dot{x}=\bar{A}(i) x+\bar{B}_{1} u+\bar{B}_{2}(i) V_{w},
$$

where

$$
\bar{A}_{i}=\left[\begin{array}{cccc}
0 & 1 & -\frac{1}{N_{g}} & 0 \\
-\frac{B_{s t i f}}{J_{r}} & \frac{1}{J_{r}} \frac{\partial T_{r 1}}{\partial \omega_{r}}-\frac{K_{d a m p}}{J_{r}} & \frac{K_{d a m p}}{J_{r} N_{g}} & \frac{1}{J_{r}} \frac{\partial T_{r 1}}{\partial \beta} \\
\frac{B_{s t i f}}{J_{g} N_{g}} & \frac{K_{d a m p}}{J_{g} N_{g}} & -\frac{K_{d a m p}}{J_{g} N_{g}^{2}}-\frac{B_{g}}{J_{g}} & 0 \\
0 & 0 & 0 & -\frac{1}{\tau}
\end{array}\right], \quad \bar{B}_{1}=\left[\begin{array}{cc}
0 & 0 \\
0 & 0 \\
0 & \frac{B_{g}}{J_{g}} \\
\frac{1}{\tau} & 0
\end{array}\right], \quad \bar{B}_{2 i}=\left[\begin{array}{c}
0 \\
\frac{T_{r 2}}{J_{r}} \\
0 \\
0
\end{array}\right] .
$$

For every operating point $\bar{x}_{i}$, through using the zero-order holder method, the above continuous-time system (18) can be transformed into the following discrete-time system:

$$
x(k+1)=A(i) x(k)+B_{1} u(k)+B_{2}(i) V_{w}(k) .
$$

According to the discussion in Section 2, considering the fact that the switching between the operating points satisfies the Markov process, then for all $i \in \varphi$, the above subsystems can compose the following discrete-time Markovian jump wind turbine control system:

$$
x(k+1)=A(r(k)) x(k)+B_{1} u(k)+B_{2}(r(k)) V_{w}(k) .
$$

Obviously, the above Markov process still satisfies the previous transition probability matrix (4).

Based on the above discussion, the stochastic property of wind speed has been brought into the dynamics of wind turbine in terms of Markov process, which can better describe the dynamic process of wind turbine. However, the tradition proportional-integral-derivative (PID) control or gain scheduling control is not appropriate for such a class of system. An interesting phenomenon of Markovian jump systems is that, ever all subsystem is stable with good dynamic response, the stochastic switchings can still cause the unstability, not to mention the dynamic response. Hence, there requires the corresponding control strategy to guarantee the control objectives when the operating points switching in the form of Markov process.

\section{Mixed $H_{2} / H_{\infty}$ control of wind turbine}

In this section, the mixed $H_{2} / H_{\infty}$ control problem is discussed for the linearized Markovian jump model of wind turbine to guarantee both the disturbance rejection and the mechanical loads objectives.

Consider the multi-objective control of the following Markovian jump model for wind turbine working up the rated wind speed:

$$
\left\{\begin{array}{l}
x(k+1)=A(r(k)) x(k)+B_{1} u(k)+B_{2}(r(k)) V_{w}(k), \\
z_{2}(k)=C_{1} x(k)+D u(k), \\
z_{\infty}(k)=C_{2} x(k)
\end{array}\right.
$$


where $z_{2}=\triangle T_{g}$ represents the generator torque fluctuation of the whole transmission mechanism similar as (17), and $z_{\infty}=\triangle \omega_{g}$ represents the regulation error due to the disturbance $V_{w}$.

The detailed operating strategy of wind turbine can be introduced as follows: When the average wind speed is below the rated wind speed (from 5 to $8.5 \mathrm{~m} / \mathrm{s}$ ), the control is designed for the maximum capture of wind energy in the variable-speed fixed-pitch mode until the rated rotor speed, i.e., to guarantee the maximum $C_{P}$ through maintaining the best tip speed ratio; When the rotor speed reaches the rated rotor speed following with the increasing wind speed (from 8.5 to $12 \mathrm{~m} / \mathrm{s}$ ), the wind turbine is operating in fixed-speed fixed-pitch mode until the rated power; When above the rated wind speed (from $12 \mathrm{~m} / \mathrm{s}$ to the cut-off wind speed), the control is designed to change the wind energy utilization coefficient of wind turbine through using the pitch controller and regulate the generator speed in order to harvest the rated electrical power, which is running in the variable-pitch fixed-speed mode, see [6]. Obviously, all the state reference values and control modes of wind turbine can be determined by the average wind speed,

However, the traditional control is designed separately according to the operating regions. But the stochastic wind speed causes the frequent switchings between different operating points and regions. Hence, we adopt the mixed $H_{2} / H_{\infty}$ control problem for system (21) to guarantee both the disturbance rejection and the mechanical loads objectives. More concretely, the controller design constraints include the $H_{\infty}$ problem for better speed regulation, and $H_{2}$ problem for optimizing control action to reduce the the generator torque fluctuation of the whole transmission mechanism.

To prove that the controlled system guarantees the disturbance rejection of level $\gamma$, let us consider the following cost function:

$$
J_{\infty}=\frac{E\left[\sum_{k=0}^{\infty} z_{\infty}^{\prime}(k) z_{\infty}(k)\right]}{E\left[\sum_{k=0}^{\infty} V_{w}^{\prime}(k) V_{w}(k)\right]} \leq \gamma^{2} .
$$

The $H_{\infty}$ performance requires that under the zero initial conditions, the systems satisfies that $J_{\infty} \leq 0$. First of all, we take the following Lyapunoy candidate

$$
V(x(k), r(k))=x^{\prime}(k) P\left(r_{k}\right) x(k), \quad r_{k}=i \in \varphi
$$

then for system (21) under the control law $u(k)=K(r(k)) x(k)$, we can obtain that

$$
E[(V(x)(k+1), r(k+1) \mid x(k), r(k)=i)-V(x(k), i)]=\left[x^{\prime}(k), V_{w}^{\prime}(k)\right] \Pi(i)\left[\begin{array}{c}
x(k) \\
V_{w}(k)
\end{array}\right],
$$

where

$$
\left.\begin{array}{c}
\left(A_{i}+B_{1 i} K_{i}\right)^{\prime} \sum_{j=1}^{N} p_{i j} P_{j}\left(A_{i}+B_{1 i} K_{i}\right)-P_{i} \\
B_{2 i}^{\prime} \sum_{j=1}^{N} p_{i j} P_{j}\left(A_{i}+B_{1 i} K_{i}\right)
\end{array}\right]
$$


Combining the definition of $J_{\infty}$, it is easy to obtain the following:

$$
\begin{aligned}
E & {\left[\left(V(x(T), r(T)) \mid x_{0}, r_{0}\right)-V\left(x_{0}, r_{0}\right)\right] } \\
& =\sum_{k=0}^{T} E[(V(x(k+1), r(k+1) \mid x(k), r(k))-V(x(k), i)] \\
& =\sum_{k=0}^{T}\left[x^{\prime}(k), V_{w}^{\prime}(k)\right] \Gamma(i)\left[\begin{array}{c}
x(k) \\
V_{w}(k)
\end{array}\right]-\left(\sum_{k=0}^{T}\left(z^{\prime}(k) z(k)-\gamma^{2} V_{w}^{\prime}(k) V_{w}(k)\right)\right),
\end{aligned}
$$

where

$$
\Gamma(i)=\left[\begin{array}{r}
\left(A_{i}+B_{1 i} K_{i}\right)^{\prime} \sum_{j=1}^{N} p_{i j} P_{j}\left(A_{i}+B_{1 i} K_{i}\right)-P_{i}+C_{2 i}^{\prime} C_{2 i} \\
B_{2 i}^{\prime} \sum_{j=1}^{N} p_{i j} P_{j}\left(A_{i}+B_{1 i} K_{i}\right) \\
\ldots \quad\left(A_{i}+B_{1 i} K_{i}\right)^{\prime} \sum_{j=1}^{N} p_{i j} P_{j} B_{2 i} \\
B_{2 i}^{\prime} \sum_{j=1}^{N} p_{i j} P_{j} B_{2 i}-\gamma^{2} I
\end{array}\right]
$$

Hence, if we have $\Gamma(i)<0$, let $T \rightarrow \infty$ and considering the zero initial condition, it reduces to that

$$
E\left[\sum_{k=0}^{\infty} z_{\infty}^{\prime}(k) z_{\infty}(k)-\gamma^{2} V_{w}^{\prime}(k) V_{w}(k)\right] \leq-E\left(V(x(T), r(T)) \mid x_{\theta}, r_{0}\right) \leq 0,
$$

which guarantees that the closed-loop system satisfies the $H_{\infty}$ performance.

Next, we need to transform the above matrix inequality into LMI form. Let $X(i)=P^{-1}(i)$ and define $\psi(i)$ and $Y(i)$ as follows: $\psi(i)=\left\{\sqrt{p_{i 1}} I, \ldots, \sqrt{p_{i N}} I\right\}, \phi(i)=\operatorname{diag}\{X(1), \ldots, X(N)\}, Y(i)=K(i) X(i)$. Pre- and post-multiplying the previous inequality $\Gamma(i)<0$ by $\phi(i)$ and using the Schur complement lemma, we get the following result:

For a given disturbance rejection of level $\gamma$, if there exist a set of symmetric and positive-definite matrices $X=(X(1), \cdots, X(N))$ and a set of matrices $Y=(Y(1), \cdots, Y(N))$, such that

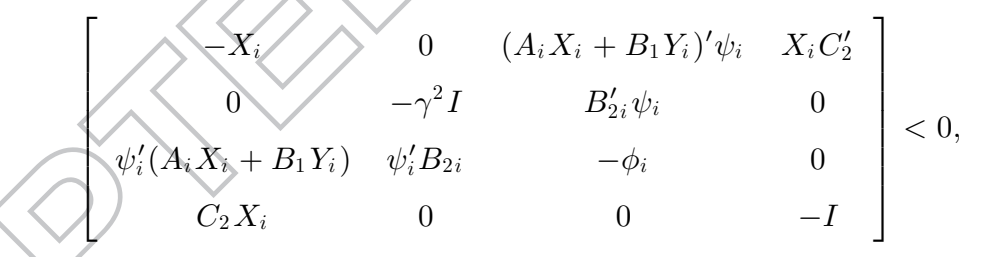

then $u(k)=K(r(k)) x(k)$ is the $H_{\infty}$ control for system (21). In this situation, the system with the controller is said to have a $H_{\infty}$ performance $\gamma$. More specifically, the system is stochastically stable and satisfies the $H_{\infty}$ performance. In other word, the wind power output of wind turbine can still track the reference input under the disturbance $V_{w}$.

On the other hand, for the mechanical load, we consider the following cost:

$$
J_{2}=E\left[\sum_{k=0}^{\infty} z_{2}(k)^{\prime} z_{2}(k)\right]
$$


Obviously, the above $H_{2}$ performance can be constrained by the trace of the cost matrix $Q$ which satisfies the following LMIs:

$$
\left[\begin{array}{cc}
Q & C_{1} X_{i}+D Y_{i} \\
X_{i} C_{1}^{\prime}+Y_{i}^{\prime} D^{\prime} & X_{i}
\end{array}\right]>0 .
$$

Combining the above discussion, this control design of wind turbine is aimed at a control $u(k)=$ $K(r(k)) x(k)$ to solve the following mixed $H_{2} / H_{\infty}$ control problem for system (21):

$$
\min _{u}\left(J_{\infty}, J_{2}\right)
$$

Obviously, the above multi-objective $H_{2} / H_{\infty}$ control design needs to minimize $J_{2}$ and $J_{\infty}$ simultaneously, which requires to seek Pareto optimal solutions to achieve the simultaneous minimization similarly as $[31,32]$. Herein, we adopt the loop algorithm to choose the Pareto optimal like point. Set the $H_{\infty}$ performance region $\gamma \in\left[\gamma_{\min }, \gamma_{\max }\right]$, then circulating solve the LMIs $(22)$ and (23) from $\gamma_{\max }$ to $\gamma_{\min }$ with a appropriate interval, and solve the suboptimal control problem $\min \operatorname{Trace}(Q)$, respectively. The criteria behind that choice were that the values of both $J_{2}$ and $J_{\infty}$ should be as small as possible for better $H_{2}$ and $H_{\infty}$ performance while a feasible solution can be obtained, which can also be adjusted following with the actual requirements from both the generator torque fluctuation and the regulation error of the generator rotor speed. If infeasible, we turn to adjust the $H_{\infty}$ performance region and repeat the above procedures until the Pareto optimal like point is achieved.

Note that, the above problem can be solved through the LMH control toolbox for Matlab easily, which also implies the final mixed $H_{2} / H_{\infty}$ state feedback controller $\widehat{K}(i)=Y(i) X(i)^{-1}$. Based on the above discussions, the procedure of designing the mixed $\mathrm{H}_{2} \mathrm{XH}_{\infty}$ control for the Markovian jump wind turbine can be given as follows:

Step 1: Classify the average wind speed into several regions containing the operating points;

Step 2: Calculate the transition probability matrix (4) between different wind speed regions through sampling the wind speed data in the separate wind speed region;

Step 3: On the each operating point, linearize the wind turbine into the corresponding linear form $(18)$;

Step 4: Transform the continuous-time system into discrete-time system, and combine the subsystems under the Markov rule;

Step 5: Choose the appropriate Pareto optimal like point, where $J_{2}$ and $J_{\infty}$ reach the expected minimum values simultaneously;

Step 6: Solve the corresponding controller gain $K_{i}$ for each operating point; Check whether the designed control satisfies the performance requirements. If necessary, repeat Step 5 until the control effectiveness is satisfied.

Following with the switching of the actual wind speed in separate operating regions $r(k)=i$, we only need to choose the corresponding state feedback $K(i)$, which guarantees the control performance of wind 
turbine. Note that, the advantage of this approach is that, we only need to adjust the control parameter for each operating point, then the stochastic negative effects of wind speed can be reduced without any further procedures.

\section{Simulation results}

In this section, the proposed method is applied on a $2 \mathrm{MW}$ wind turbine with the parameters shown in the following Table 3. To verify the effectiveness of proposed control method, comprehensive simulation studies are carried out based on Wind Turbine Blockset Toolbox in Matlab/Simulink platform. The Blockset is developed by Aalborg University and RISOE DTU National Laboratory, which has been used as a general developer tool for other three simulation tools: Saber, DIgSILENT and HAWC 34 .

The wind-power utilization coefficient $C_{p}(\lambda, \beta)$ is with the following coefficients:

$$
c_{1}=0.5176, c_{2}=116, c_{3}=0.4, c_{4}=5, c_{5}=21, c_{6}=0.0068, c_{7}=0.08, c_{8}=0.035 \text {. }
$$

The historical wind speed data is collected from the distributed control system (DCS) corresponding to a wind turbine installed in the northeast of China. The sampling time is $1 s$, and the sampling data contain 120000 points, see Fig. 2. As follows, we present the design procedures and the technical details mentioned in Section 3.

Step 1: From Fig. 2 and by (15), we can compute the average wind speed as shown in Fig. 3. Herein, for the pitch control of wind turbine, we only need to classify the above rated wind speed into several regions. Besides, from Fig. 3, the vast majority of wind speed is under $20 \mathrm{~m} / \mathrm{s}$. Hence, we adopt the following classifying strategy as in Table 4 . From 12 to $20 \mathrm{~m} / \mathrm{s}$, each wind speed subregion is fixed with $1 \mathrm{~m} / \mathrm{s}$ range, and the corresponding operating point is chosen at the middle position of each subregion, such as $12.5 \mathrm{~m} / \mathrm{s}$, etc.

Step 2: Through analysing the data of average wind speed in Fig. 3, the number of the observed transitions between the subregions can be computed as follow:

$\left.\begin{array}{cccccccc}2672 & 182 & 0 & 0 & 0 & 0 & 0 & 0 \\ 183 & 1993 & 148 & 0 & 0 & 0 & 0 & 0 \\ 0 & 148 & 1610 & 118 & 0 & 0 & 0 & 0 \\ 0 & 0 & 118 & 1038 & 72 & 0 & 0 & 0 \\ 0 & 0 & 0 & 72 & 699 & 60 & 0 & 0 \\ 0 & 0 & 0 & 0 & 60 & 349 & 35 & 0 \\ 0 & 0 & 0 & 0 & 0 & 35 & 282 & 21 \\ 0 & 0 & 0 & 0 & 0 & 0 & 21 & 136\end{array}\right]$


Then, according to (3), we can obtain the following probability transition matrix:

$$
P_{i j}=\left[\begin{array}{cccccccc}
0.9359 & 0.0783 & 0 & 0 & 0 & 0 & 0 & 0 \\
0.0641 & 0.8579 & 0.0789 & 0 & 0 & 0 & 0 & 0 \\
0 & 0.0637 & 0.8582 & 0.0961 & 0 & 0 & 0 & 0 \\
0 & 0 & 0.0629 & 0.8453 & 0.0866 & 0 & 0 & 0 \\
0 & 0 & 0 & 0.0586 & 0.8412 & 0.1351 & 0 & 0 \\
0 & 0 & 0 & 0 & 0.0722 & 0.7860 & 0.1036 & 0 \\
0 & 0 & 0 & 0 & 0 & 0.0788 & 0.8343 & 0.1338 \\
0 & 0 & 0 & 0 & 0 & 0 & 0.0621 & 0.8662
\end{array}\right]
$$

Obviously, the current wind speed only shifts to the closed upper subregion, the lower one or the remaining one. Then, the Markov process $r(k)$ has been established with the probability transition matrix (24) for the average wind speed in Fig. 3. In this situation, the stochastic property of the average wind speed has been extracted by the Markov process $r(k)$.

Step 3: To obtain the wind turbine control system (18) with the coefficients in Table 5, we adopt the following linearization procedures: Firstly, we determine the operating points when the average wind speed $V_{s}$ is fixed at the middle of each subregion. By (7), considering the rated rotor speed, we can calculate the tip speed ratio for each subregion. Through checking the $\lambda$ - $\beta$ look-up table and using the linear interpolation method, the corresponding referenced pitch angle $\bar{\beta}_{i}$ can be obtained, which sustains the operating points $\bar{x}_{i}=\left[\bar{\theta}_{i}(r / s), \bar{\beta}_{i}\left({ }^{\circ}\right), \bar{\omega}_{\eta i}(r / s), \vec{\omega}_{g m i}(r / s)\right]^{\prime}$ as shown in Table 5 . Then, the corresponding coefficients $\bar{A}_{i}, \bar{B}_{1 i}$ and $\bar{B}_{2 i}$ can be determined directly.

Step 4: The wind turbine control system (18) can be transformed into the discrete-time case (21) through using the zero-order holder method, which can be realized through using the Matlab software directly. Note that, the coefficients $B_{1}$ and $B_{2}$ can be achieved through combining the $u$ and $V_{w}$ into a common input $\bar{u}$. Similarly procedures for $C_{1}$ and $C_{2 i}$.

Step 5: From the viewpoint of numerical calculation, all possible feasible solutions for the $H_{\infty}$ and $H_{2}$ performances can be solved simultaneously for a given appropriate region related to $\gamma$ or $\operatorname{Trace}(Q)$. Herein, we take $\gamma \in(0,1)$ and all possible solutions are presented in Fig. 4. Choose the Pareto-optimallike point as $\gamma=0.1$ and $\operatorname{Trace}(Q)=137.4$, which are corresponding to the $H_{\infty}$ performance and $H_{2}$ performance, respectively.

Step 6: Consider the wind turbine control system (21) with the coefficients $A_{i}, B_{1}, B_{2 i}, C_{1 i}$ and $C_{2 i}$, set the disturbance rejection performance $\gamma=0.1$, and solve the LMIs (22) and (23), which reduces to the corresponding control gain $K_{i}$ and sustains the control input $\beta_{r}$ and $\omega_{z}$ as in Fig. 8 and 9.

Next, to show the efficiency of the proposed control strategy, we adopt a period of actual above rated wind speed as in Fig. 5 from the point 71851s to 72940s in Fig. 2, which can be decomposed into the average wind speed $V_{s}$ in Fig. 6 and disturbance wind speed $V_{w}$ in Fig. 7, respectively.

Following with the switchings of average wind speed in Fig. 6, the switchings of operating points can 
be reflected by the referenced pitch angle $\bar{\beta}_{i}$ as shown in Fig. 8, where the control input of the proposed method and PID are also given. Through substituting the feedback control gain $K_{i}$ following with the switching of operating points, the control effectiveness can be found in the Fig. 10-24.

Although the PI control is usually adopted in practice, the gain-scheduled PID control is adopted for fully comparison as shown in Fig. 10, where the operating regions have been classified as in Table 5 . In order to realize the undisturbed switching control with better dynamic response, the PID control has been improved through using the linear interpolation method. More specifically, denote the current time measured wind speed as $V_{k}$, and the previous time as $V_{k-1}$, we adopt the following control strategy:

i) When the wind speed changes smaller and in the same operating region, set $\beta_{r}=\bar{\beta}_{i}$.

ii) When the wind speed changes larger and over operating regions, take

$$
\left\{\begin{array}{l}
\beta_{r}=\alpha \bar{\beta}_{i-1}+(1-\alpha) \bar{\beta}_{i}, \text { when wind speed increase } \\
\beta_{r}=(1-\alpha) \bar{\beta}_{i-1}+\alpha \bar{\beta}_{i}, \text { when wind speed decrease }
\end{array}\right.
$$

where

$$
\alpha=\frac{\left|V_{k-1}-V_{i-1}\right|}{\left|V_{k-1}-V_{i-1}\right|+\left|V_{k}-V_{i-1}\right|} .
$$

In such a way, the gain-scheduled PID control can better handle the case of wind turbine with the high-frequency wind speed fluctuation and reduce the switching fluctuation. For each operating region, the PID control has been tuned with a high quality. However, due to the frequent switchings of operating points and the turbulent wind speed, the rotor speed and generator speed still exist many fluctuations. With the proposed method, the control effect has been improved significantly in Fig. 11-17.

Due to the proposed $H_{2} / H_{\infty}$ optimal control, the mechanical torques including the rotor torque $T_{r}$, the drag torque $T_{d}$ and the generator torque $T_{g}$ have also been improved with less fluctuations in Fig. 13, 14 and 15, respectively, which are more smoothing compared with the PID control, and have shown significance improvements on the disturbance rejection. Due to these improvements especially on $T_{g}$, less fluctuations for the mechanical torques have been guaranteed compared with PID control, which can reduce the fatigue loads efficiently. Meanwhile, the mechanical power $P$ has been regulated with less fluctuations as shown in Fig. 16 and 17.

To better quantify these improvements, the frequency analysis under the proposed method and PID control are shown in Fig. 19-22, which describes the power spectrum density (PSD) estimation of the rotor speed $\omega_{k}$, the generator speed $\omega_{g}$, the generator torque $T_{g}$ and power $P$ through using the music method. It can be found that, there all exist two spikes near the frequency 0.242 and 0.398 , which are caused by the turbulence wind speed as shown in Fig. 18. The PID controller can reduce the two spikes to a certain extent, while the proposed controller can reduce the interference further, and the distribution of the signal power is concentrated in the low frequency band, which shows the disturbance rejection effeetiveness of the proposed method.

Moreover, the frequency statistics of the generator torque and power variations under the proposed method and PID control are shown in Fig. 23 and 24. Obviously, the frequency statistics of the proposed 
method are much more concentrated on the region nearer to 0 compared with the PID control, which shows that few fluctuations have been guaranteed for both the generator torque and mechanical power simultaneously. More concretely, better frequency statistics of generator torque variations can guarantee the fatigue loads as small as possible, and better frequency statistics of power variations implies less volatility of the output power $P$, which can reduce the control difficulty of the DFIG to guarantee higher-quality power.

Based on the above discussion, the power quality on the mechanical side have been improved with less volatility and mechanical loads, which can reduce the reference value variation of the DFIG side within the same grid condition. Hence, through combining the stochastic wind speed into the control design of wind turbine, the designed mixed $H_{2} / H_{\infty}$ control can provide a feasible tuning technique on the mechanical power and fatigue load performances. Moreover, this study is mainly concentrated on the case of above the rated wind speed for simplicity, which can be generalized to the full wind speed region.

\section{Conclusion}

This paper has proposed a Markovian jump model for the dynamic process of wind turbine driven by the switching wind speed, and discussed the mixed $H_{2} / H_{\infty}$ control problem. Through sampling the steady wind speed data in the separate wind speed region, the system is switching from one mode to another, and the switching rule is modeled into a Markov process. Then, the corresponding mixed $H_{2} / H_{\infty}$ control can guarantee both the disturbance rejection and the fatigue loads objectives, which has combined the switching rule into the control design of wind turbine effectively. Further efforts could be concentrated on the controller improvement for the full wind speed region to deal with the switchings between partial and full load.

\section{References}

[1] S. M. Muyeen, Wind energy conversion systems: technology and trends, Berlin: Springer, 2012.

[2] A. R. Jha, Wind turbine technology, Florida: CRC press, 2011.

[3] S. Mathew, G. S. Philip, Advances in wind energy conversion technology, Berlin: Springer, 2011.

[4] L.Munteanu, A. L. Bratcu, N. A. Cutuluis, Optimal control of wind energy systems, London: Springer, 2008.

(5] T. Senjyu, R. Sakamoto, N. Urasaki, et al, "Output power leveling of wind turbine generator for all operating regions by pitch angle control," IEEE Transactions on Energy Conversion, vol. 214, pp.

$67-475,2006$. 
[6] Y. El-Tous, "Pitch angle control of variable speed wind turbine," American Journal of Engineering and Applied Sciences, vol. 2, pp. 118-120, 2008.

[7] F. Lescher, J. Y. Zhao, P. Borne, "Robust gain scheduling controller for pitch regulated variable speed wind turbine," Studies in Informatics and Control, vol. 14, pp. 299-315, 2005.

[8] F. D. Bianchi, R. J. Mantz, C. F. Christiansen, "Gain scheduling control of variable speed wind energy conversion systems using quasi-LPV models," Control Engineering Practice, vol. 13, pp. 247-255, 2005.

[9] M. J. Balas, A. Wright, M. Hand, et al, "Dynamics and control of horizontal axis wind turbines" The American Control Conference, Denver, Colorado, USA, pp. 3781-3793, 2003.

[10] C. Slotha, T. Esbensenb, J. Stoustrup, "Robust and fault-tolerant linear parameter-varying control of wind turbines", Mechatronics, vol. 21, pp. 645-659, 2011.

[11] F. D. Bianchi, H. D. Battista, R. J. Mantz, Wind turbine control systems principles, modelling and gain scheduling design, Netherlands: Springer, 2007.

[12] S. A. Salle, D. Reardon, W. E. Leithead, M. J. Grimble, "Review of wind turbine control," Int. J. Control, vol. 52, pp. 1295-1310, 1990.

[13] E. S. Abdin, W. Xu, "Control design and dynamic performance analysis of a wind turbine-induction generator unit," IEEE Trans. On EC., vol. 15, pp. 91-96, 2000.

[14] H. Nfaoui, H. Essiarab, A. A. M. Sayigh, "A stochastic Markov Chain model for simulating wind speed time series at Tangiers, Morocco," Renewable Energy, vol. 29, pp. 1407-1418, 2004.

[15] A. D. Sahin, Z. Sen, "First-order Markov chian approach to wind speed modelling," Journal of Wind Engineering and Industrial Aerodynamics, vol. 89, pp. 263-269, 2001.

[16] H. Kantz, D. Holstein, M. Ragwitz, N. K. Vitanov, "Markov chain model for turbulent wind speed datas," Physica A, vol, 342, pp. 315-321, 2004.

[17] F. O. Hocaoglu, O. N. Gerek, M. Kurban, "A novel wind speed modelling approach using atmospheric pressure observations and hidden Markov models," Journal of Wind Engineering and Industrial Aerodynamics, yol, 98, pp. 472-481, 2010.

[18] B. L. Nelson, Stochstic Modeling (Analysis 8 Simulation), New York: Mac Graw-Hill, 1995.

[19] B. R. Karthikeya, R. J. Schutt, "Overview of Wind Park Control Strategies," IEEE Transactions on Sustainable Energy, vol. 5, pp. 416-422, 2014.

[20] T. Bakka, H. R. Karimi, "Multi-Objective Control Design with Pole Placement Constraints for Wind Turbine System," Advances on Analysis and Control of Vibrations-Theory and Applications, Intech, 2012. 
[21] Y. Hu, J. Z. Liu, Z. W. Lin, "LPV T-S fuzzy gain scheduling control of WTGS below rated wind speed," The 26th Chinese Control and Decision Conference (CCDC), pp. 3328-3333, 2014.

[22] Y. G. Niu, X. M. Li, Z. W. Lin, "Decentralized coordinated neural control of doubly fed induction generator based wind farm for power system stability support", Journal of Renewable and Sustainable Energy, vol. 6, no. 4, 043126, 2014.

[23] F. A. Inthamoussou, F. D. Bianchi, H. De Battista, R. J. Mantz, "LPV Wind Turbine Control With Anti-Windup Features Covering the Complete Wind Speed Range," IEEE Transactions on Energy Conversion, vol. 29, no. 1, pp. 259-266, 2014.

[24] Z. W. Lin, Y. Lin, W. H. Zhang, "A unified design for state and output feedback $H_{\infty}$ control of nonlinear stochastic Markovian jump systems with state and disturbance-dependent noise," Automatica, vol. 41, pp. 2955-2962,2009.

[25] Z. W. Lin, J. Z. Liu, W. H. Zhang, Y. G. Niu, "Stabilization of interconnected nonlinear stochastic Markovian jump systems via dissipativity approach," Automatica, vol.47, pp. 2796-2800, 2011.

[26] M. Mariton, Jump Linear Systems in Automatic Control, Marcel Dekker, 1990.

[27] P. Shi, F. Li, A survey on Markovian jump systems: modeling and design, International Journal of Control, Automation and Systems 2015; 13:1-16.

[28] L. Pao, K. Johnson, "A tutorial on the dynamics and control of wind turbines and wind farms", The Proceedings of the Americal Control Conference, St. Louis, MO, pp. 2076-2089, 2009.

[29] J. H. Laks, L. Pao, A. D. Wright, "Control of wind turbines: Past, present, and future", The Proceedings of the American Control Conference, St. Louis, MO, pp. 2096-2103, 2009.

[30] F. Wu, X. Zhang, P. Ju, etc, "Decentralized Nonlinear Control of Wind Turbine With Doubly Fed Induction Generator", LEEE Transactions on Power Systems, vol. 23, no. 2, pp. 613-621, 2008.

[31] P. F. Odgaard, "On Usage of Pareto curves to Select Wind Turbine Controller Tunings to the Wind Turbulence Level", 2015 European Control Conference (ECC), Linz, Austria, pp. 1534-1539, 2015.

[32] P. F. Odgaard, L.F. S. Larsen, R. Wisniewski, T. G. Hovgaard, "On Using Pareto optimality to tune a linear model predictive controller for wind turbines", Rnenewable Energy, vol. 87, pp. 884-891, 2016.

(33] S. M. Muyeen, Md. H. Ali, R. Takahashi, etc, "Comparative study on transient stability analysis of wind turbine generator sysem using different drive train models", IET Renew. Power Gener., vol. 1, no. 2, pp. 131-141, 2007.

[34] F. Iov, A. D. Hansen, P. Soerensen, F. Blaabjerg, Wind Turbine Blockset in Matlab/Simulink, Aalborg, Denmark: Institute of Energy Technology, Aalborg University, 2004. 


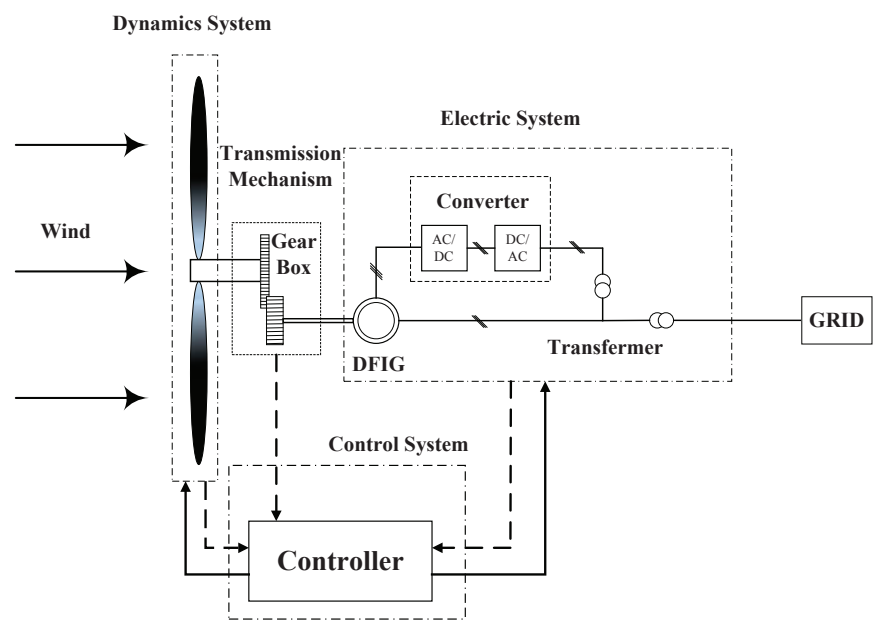

Fig. 1: The structure of wind turbine control system
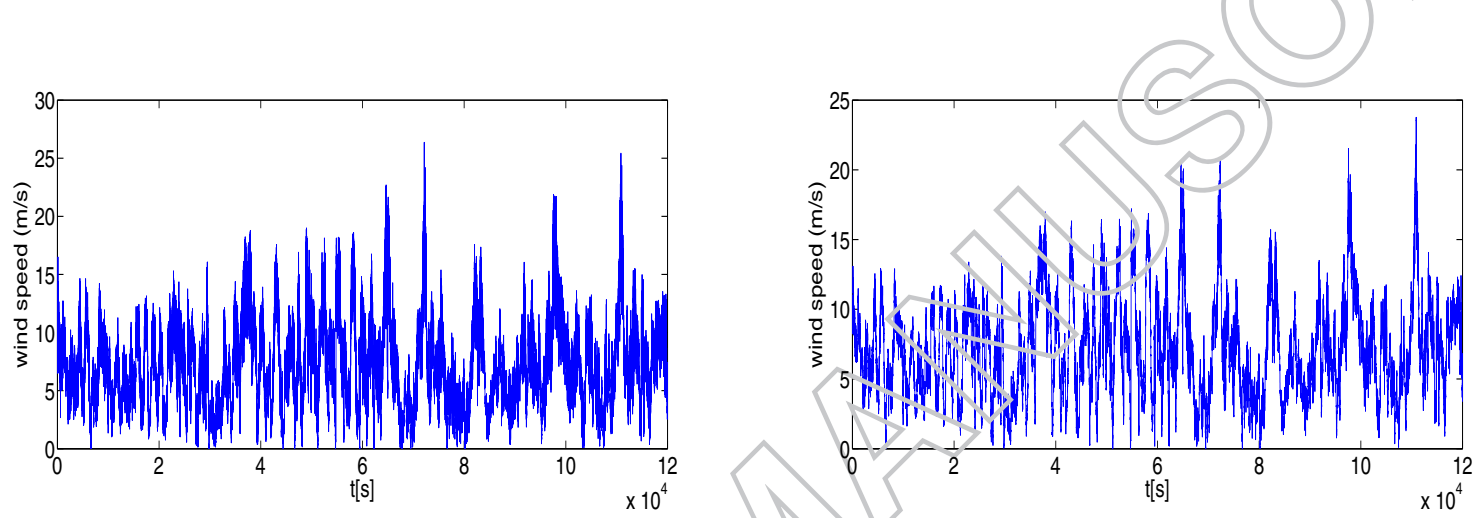

Fig. 2: The actual wind speed of wind turbine

Fig. 3: The average wind speed of wind turbine

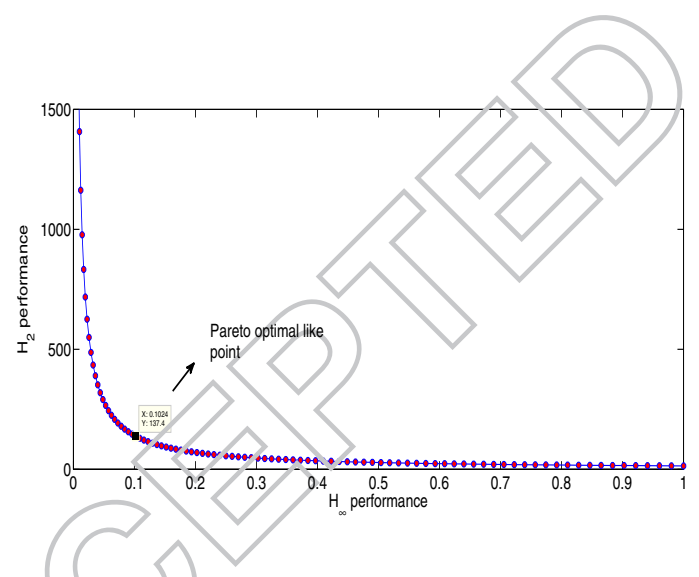

Fig. 4: The relationship of $H_{\infty}$ and $H_{2}$ performance

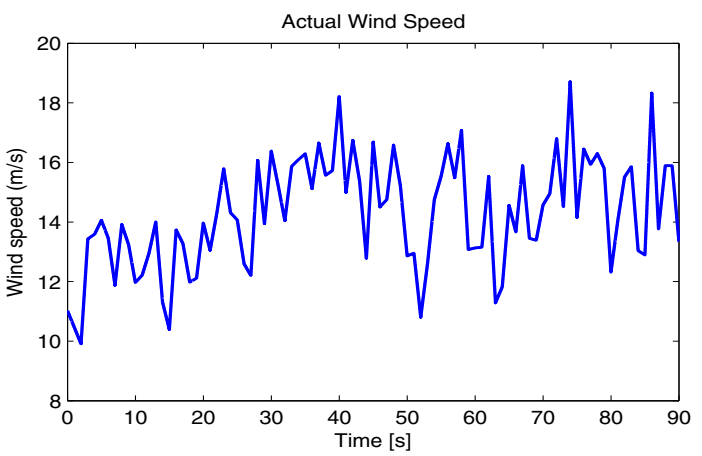

Fig. 5: The acutal wind speed 


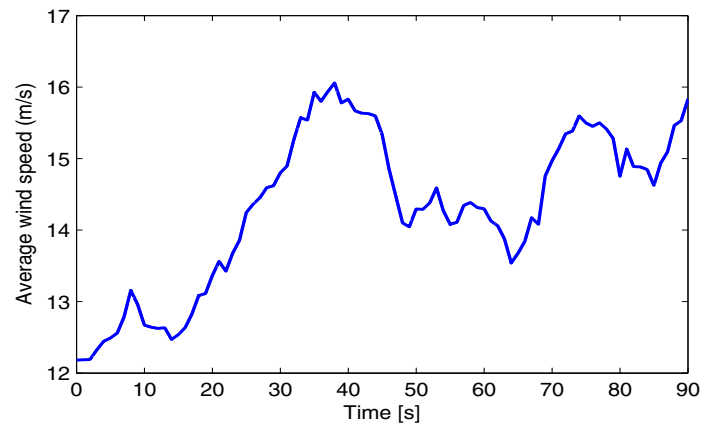

Fig. 6: The average wind speed

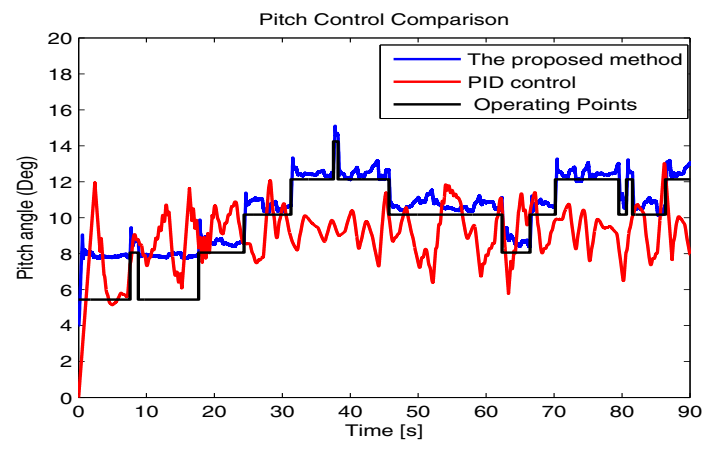

Fig. 8: Operation switchings and pitch control $\beta_{r}$

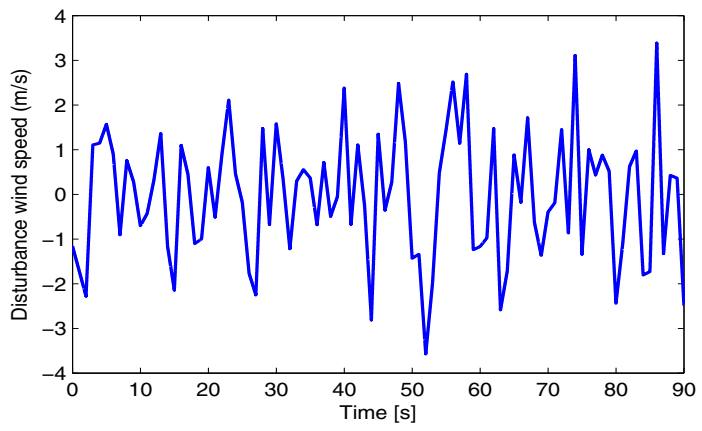

Fig. 7: The disturbance wind speed

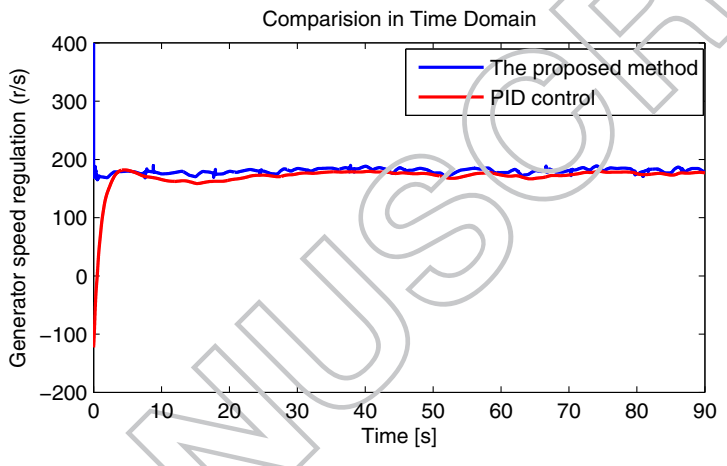

Fig. 9: The generator speed regulation $\omega_{z}$

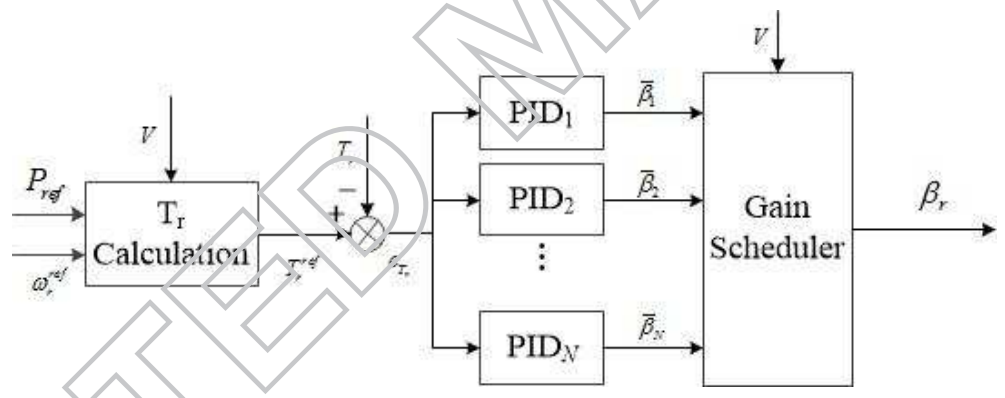

Fig. 10: The structure of wind turbine PID control system 


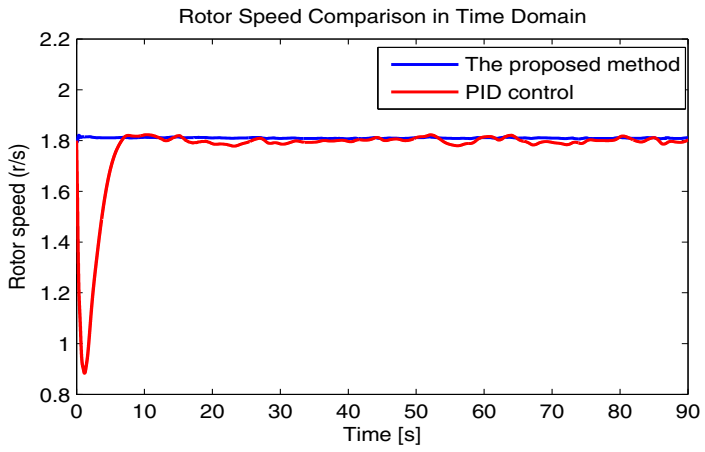

Fig. 11: The rotor speed $\omega_{r}$

Fig. 13: The rotor torque $T_{r}$

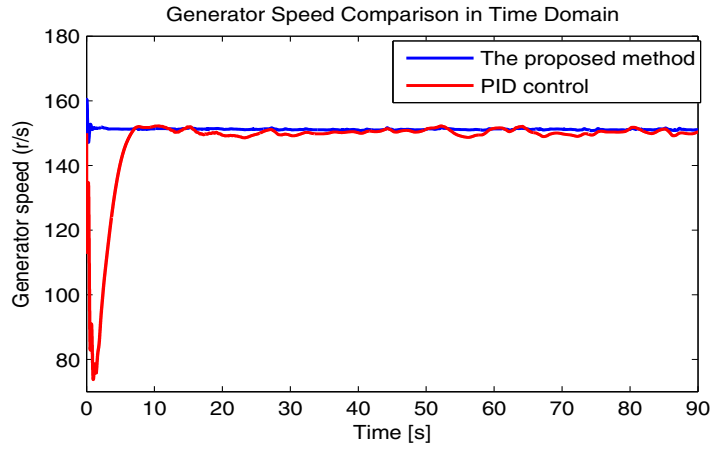

Fig. 12: The generator speed $\omega_{g}$

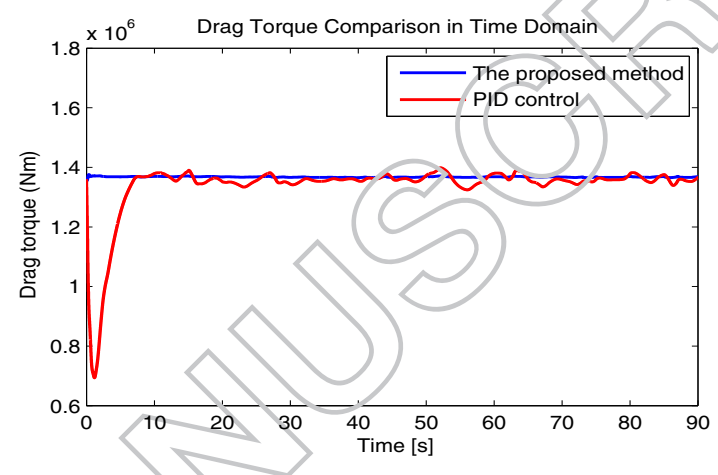

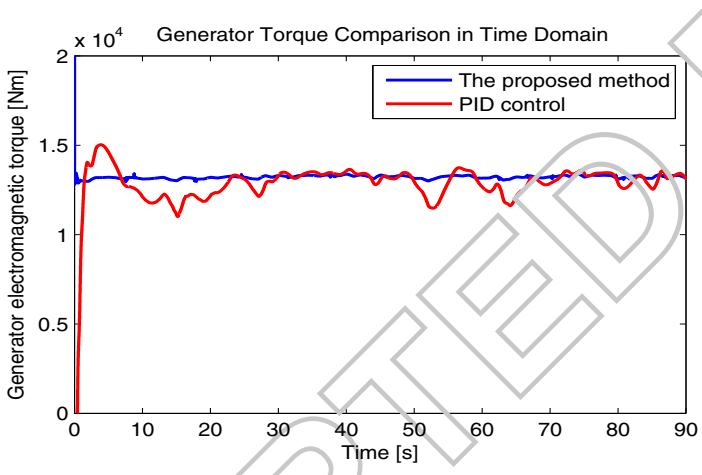

Fig. 15: The generator electromagnetic torque $T_{g}$
Fig. 14: The drag torque $T_{d}$

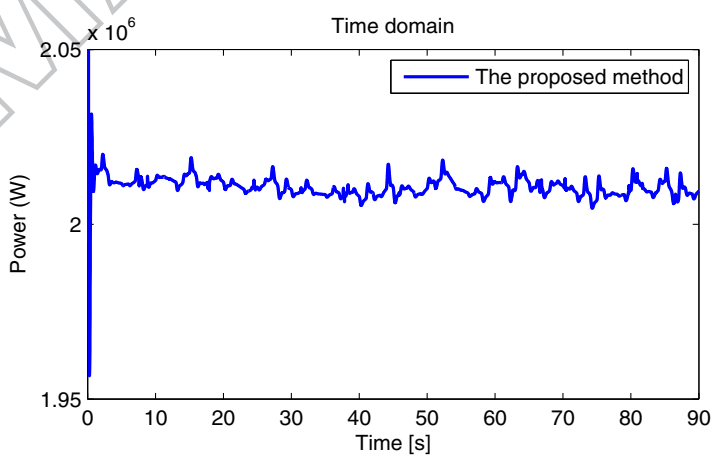

Fig. 16: The mechanical power $P$ 


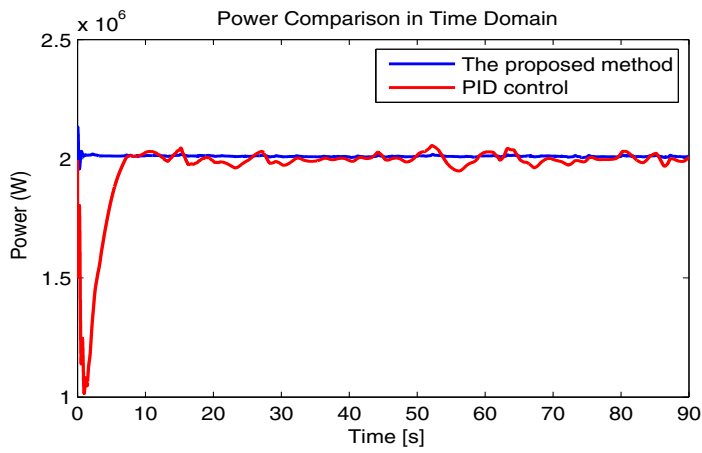

Fig. 17: Comparison of mechanical power $P$

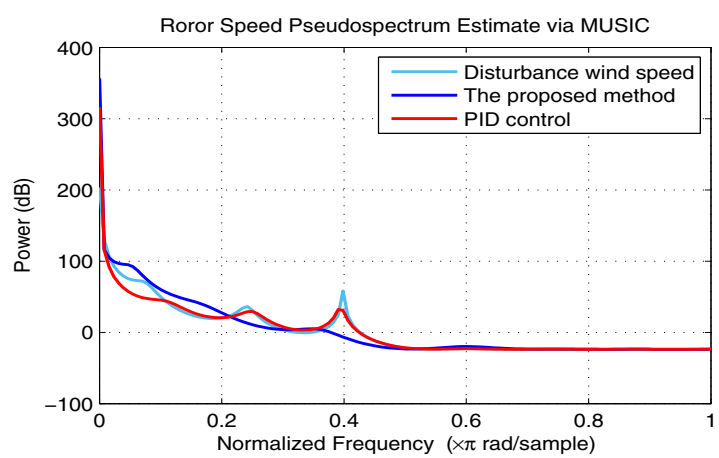

Fig. 19: PSD estimation of rotor speed $\omega_{r}$

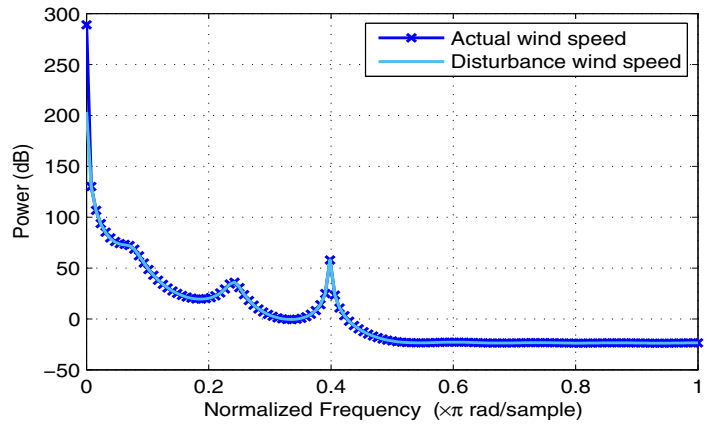

Fig. 18: PSD estimation of wind speed $V$ and $V_{u}$

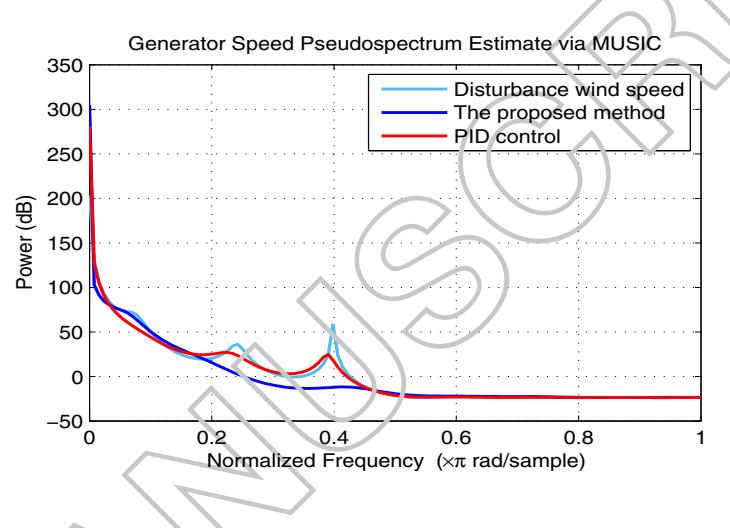

Fig. 20: PSD estimation of generator speed $\omega_{g}$
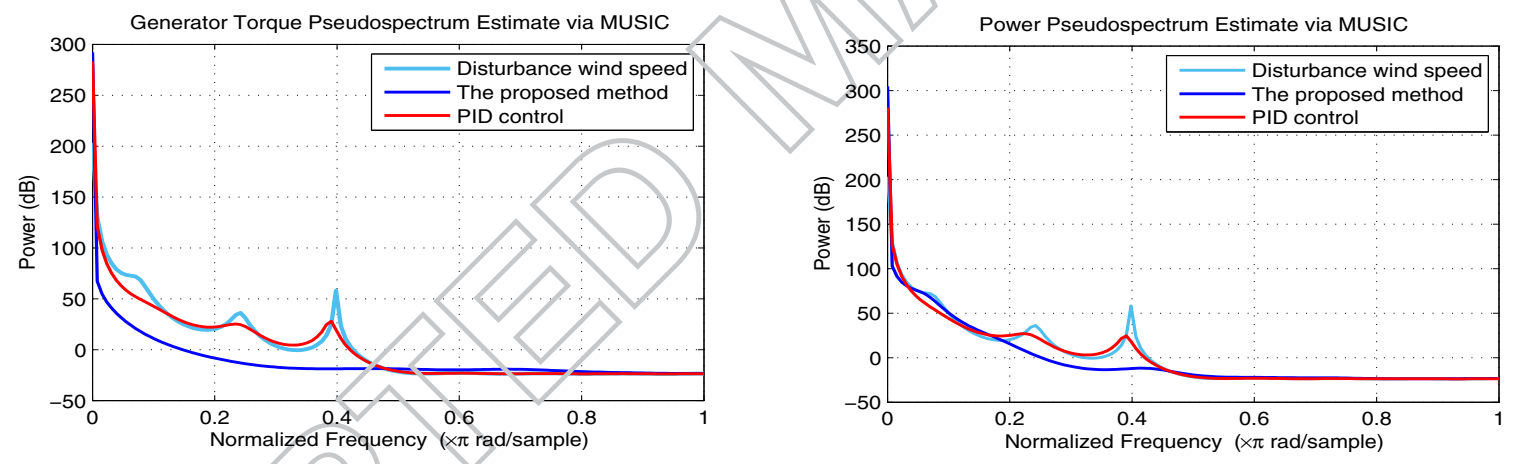

Fig. 21: PSD estimation of generator torque $T_{g}$

Fig. 22: PSD estimation of mechanical power $P$ 


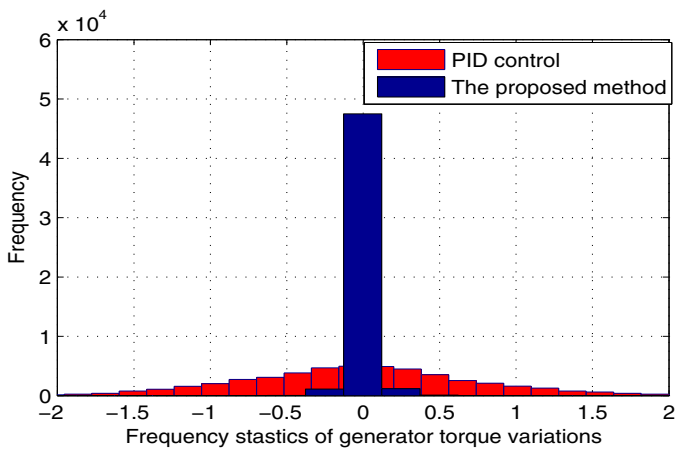

Fig. 23: Frequency statistics of $T_{g}$ variations

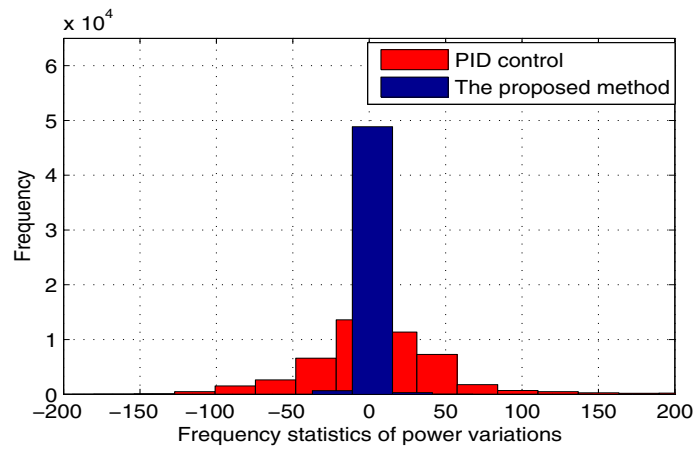

Fig. 24: Frequency statistics of power variations

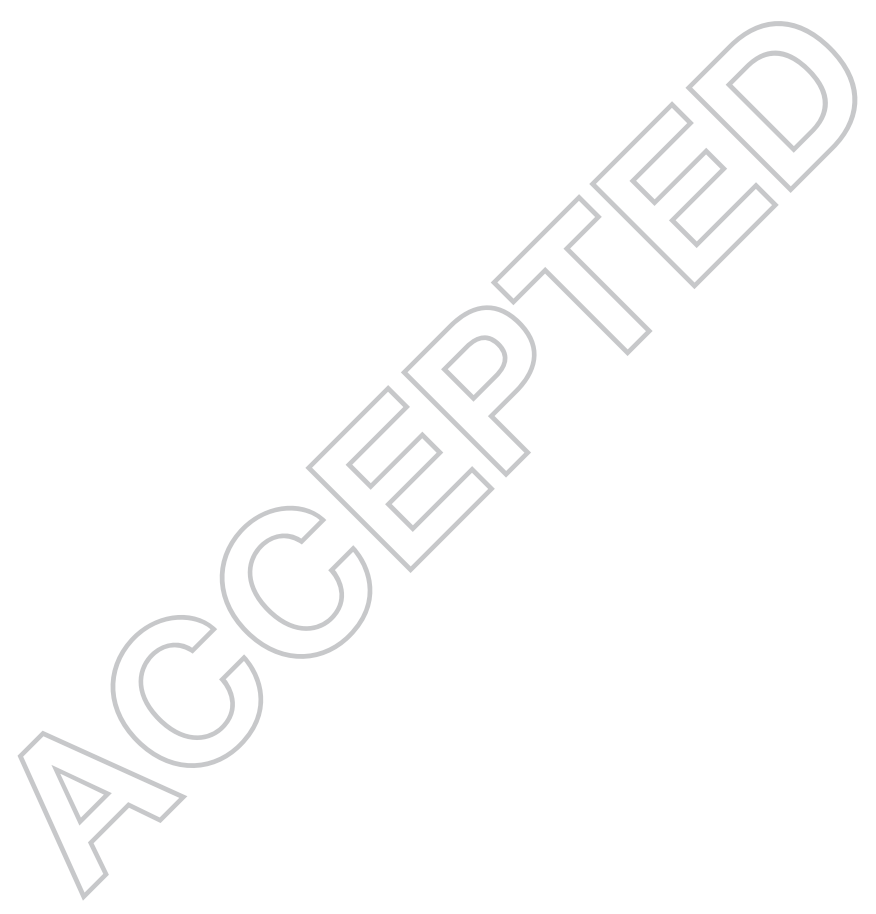


Table 1: Average Wind Speed Category

\begin{tabular}{c|c}
\hline \hline Category no. & Wind speed boundaries $(\mathrm{m} / \mathrm{s})$ \\
\hline \hline 1 & $V_{\text {rated }} \leq V_{s} \leq V_{1}$ \\
\hline 2 & $V_{1} \leq V_{s} \leq V_{2}$ \\
\hline$\vdots$ & $\vdots$ \\
\hline $\mathrm{N}$ & $V_{N-1} \leq V_{s} \leq V_{\text {cut }- \text { out }}$ \\
\hline \hline
\end{tabular}

Table 2: Operating Subregions Category

\begin{tabular}{c|l|l}
\hline \hline$i$ & Wind speed boundaries & Operating point $\bar{x}_{i}$ \\
\hline \hline 1 & $V_{\text {rated }} \leq V_{s} \leq V_{1}$ & $\bar{x}_{1}=\left[\bar{\theta}_{1}, \bar{\omega}_{r 1}, \bar{\omega}_{g 1}, \bar{\beta}_{1}\right]^{\prime}$ \\
\hline 2 & $V_{1} \leq V_{s} \leq V_{2}$ & $\bar{x}_{2}=\left[\bar{\theta}_{2}, \bar{\omega}_{r 2}, \bar{\omega}_{g 2}, \bar{\beta}_{2}\right]^{\prime}$ \\
\hline$\vdots$ & $\vdots$ & $\vdots$ \\
\hline $\mathrm{N}$ & $V_{N-1} \leq V_{s} \leq V_{N}$ & $\bar{x}_{N}=\left[\bar{\theta}_{N}, \bar{\omega}_{r N}, \bar{\omega}_{g N}, \bar{\beta}_{N}\right]^{\prime}$ \\
\hline \hline
\end{tabular}

Table 3: Wind Turbine Parameters

\begin{tabular}{l|l}
\hline \hline$R$ & $40 \mathrm{~m}$ \\
\hline$\rho$ & $1.25 \mathrm{Kg} / \mathrm{m}^{3}$ \\
\hline$\tau$ & $50 \mathrm{~ms}$ \\
\hline$J_{r}$ & $4.95 \times 10^{6} \mathrm{~kg} \cdot \mathrm{m}^{2}$ \\
\hline $\mathrm{J}_{g}$ & $90 \mathrm{~kg} \cdot \mathrm{m}^{2}$ \\
\hline$N_{g}$ & 83.531 \\
\hline$B_{\text {stif }}$ & $1.14 \times 10^{8} \mathrm{~N} / \mathrm{m}$ \\
\hline$K_{\text {damp }}$ & $7.55658 \times 10^{5} \mathrm{Nm} /(\mathrm{rad} / \mathrm{s})$ \\
\hline$B_{g}$ & $400 \mathrm{Nm} /(\mathrm{rad} / \mathrm{s})$ \\
\hline \hline
\end{tabular}


Table 4: Average Wind Speed Category

\begin{tabular}{c|c}
\hline \hline Category no. & Wind speed boundaries $(\mathrm{m} / \mathrm{s})$ \\
\hline \hline 1 & $12 \leq V_{s} \leq 13$ \\
\hline 2 & $13 \leq V_{s} \leq 14$ \\
\hline$\vdots$ & $\vdots$ \\
\hline 8 & $19 \leq V_{s} \leq 20$ \\
\hline \hline
\end{tabular}

Table 5: Operating Subregions Category

\begin{tabular}{|c|c|c|c|c|}
\hline \hline$i$ & $V_{s}(\mathrm{~m} / \mathrm{s})$ & $\lambda$ & $\mathrm{C}_{p}$ & $\bar{x}_{i}=\left[\bar{\theta}_{i}, \bar{\beta}_{i}, \bar{\omega}_{r i}, \bar{\omega}_{g m i}\right]^{\prime}$ \\
\hline \hline 1 & 12.5 & 5.8240 & 0.3259 & $\bar{x}_{1}=[0,5.4452,1.8,150.4]^{\prime}$ \\
\hline 2 & 13.5 & 5.3926 & 0.2587 & $\bar{x}_{2}=[0,8.0591,1.8,150.4]^{\prime}$ \\
\hline 3 & 14.5 & 5.0207 & 0.2088 & $\bar{x}_{2}=[0,10.1695,1.8,150.4]^{\prime}$ \\
\hline 4 & 15.5 & 4.6968 & 0.1710 & $\bar{x}_{4}=[0,12.1346,1.8,150.4]^{\prime}$ \\
\hline 5 & 16.5 & 4.4121 & 0.1417 & $\bar{x}_{5}=[0,14.2455,1.8,150.4]^{\prime}$ \\
\hline 6 & 17.5 & 4.1600 & 0.1188 & $\bar{x}_{6}=[0,16.4044,1.8,150.4]^{\prime}$ \\
\hline 7 & 18.5 & 3.9351 & 0.1005 & $\bar{x}_{7}=[0,19.2327,1.8,150.4]^{\prime}$ \\
\hline 8 & 19.5 & 3.7333 & 0.0859 & $\bar{x}_{8}=[0,22.4339,1.8,150.4]^{\prime}$ \\
\hline \hline
\end{tabular}

